\title{
Erratum to: Contemporary Reviews of Mine Water Studies in Europe, Part 1
}

\author{
Christian Wolkersdorfer $\cdot$ Rob Bowell · Jaime M. Amezaga • Adeline Kroll • \\ Adam P. Jarvis • Ben Rees • Erik Puura - Wiel M. H. Miseré • Roy W. M. G. Wings • \\ Peter Bajtoš • Leopold Weber • Blanka Sárváryné-Szentkatolnay • \\ Carlo Alberto Garzonio · Paul L. Younger
}

Published online: 19 June 2012

(C) Springer-Verlag 2012

Erratum to: Mine Water and the Environment (2004)

23:162-182

DOI 10.1007/s10230-004-0060-0

The names of some of the authors of this section were inadvertently omitted in the original publication. We regret this omission and provide all of the authors' names here:

The online version of the original article can be found under doi:10.1007/s10230-004-0060-0.

\section{Wolkersdorfer ( $\square)$}

Technische Universität Bergakademie Freiberg,

Lehrstuhl für Hydrogeologie, Gustav-Zeuner-Str. 12,

09596 Freiberg/Sachsen, Germany

e-mail: christian@wolkersdorfer.info

R. Bowell

SRK Consulting, Windsor Court, 1 Windsor Place,

Cardiff CF10 3BX, Wales, UK

\section{J. M. Amezaga}

School of Civil Engineering and Geosciences,

University of Newcastle upon-Tyne,

Newcastle upon-Tyne NE1 7RU, UK

A. Kroll

IPTS, Joint Research Centre, European Commission, Isla de la Cartuja, Edificio Expo-WTC, C/Inca Garcilaso, s/n, 41092 Sevilla, Spain

\section{A. P. Jarvis}

Hydrogeochemical Engineering Research and Outreach (HERO)

Group, University of Newcastle, Newcastle upon Tyne

NE1 7RU, UK

B. Rees

SRK Consulting, Windsor Court, 1-3 Windsor Place,

Cardiff CF10 3BX, UK
Wolkersdorfer, Christian; Bowell, Rob; Amezaga, Jaime M.; Kroll, Adeline; Jarvis, Adam P.; Rees, Ben; Puura, Erik; Miseré, Wiel M. H.; Wings, Roy W. M. G.; Bajto, Peter; Weber, Leopold; Sárváryné-Szentkatolnay, Blanka; Garzonio, Carlo Alberto; Younger, Paul L.

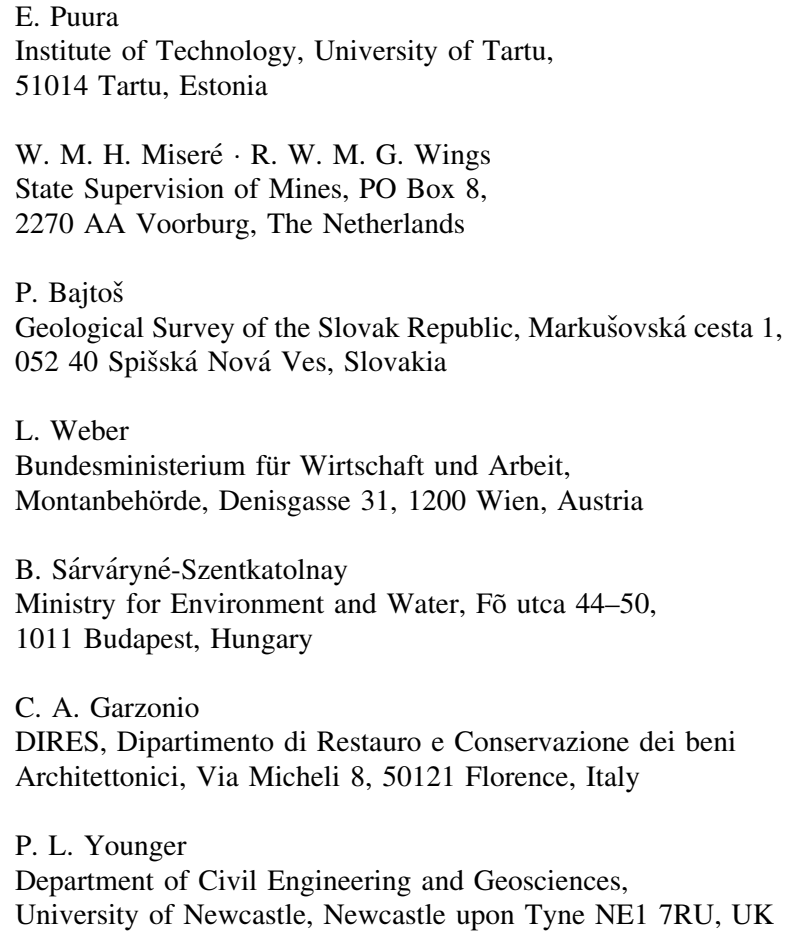

